\title{
Dissipation patterns of acrinathrin and metaflumizone in Aster scaber
}

\author{
Somin Lee ${ }^{1,2}$, Rakdo Ko ${ }^{1}$, Kwanghun Lee ${ }^{1}$, Jinchan Kim ${ }^{1}$, Seokhyeon Kang ${ }^{1}$ and Jiho Lee ${ }^{1 *}$ (D)
}

\begin{abstract}
The establishment of preharvest residue limits (PHRLs) is important to minimize damage to producer and consumers caused by agricultural products which pesticide residue exceeds maximum residue limits (MRLs). Dissipation patterns of acrinathrin and metaflumizone in Aster scaber in greenhouse were studied during 10 days in order to determine a pre-harvest interval after application. Acrinathrin and metaflumizone were applied in two different greenhouse, located in Taean-gun (field 1) and Gwangyang-si (field 2). Samples were collected at 0, 1, 2, 3, 5, 7, and 10 days after insecticides application. The recoveries of two insecticides analyzed by LC-MS/MS and HPLC-DAD were ranged from 77.1 to $111.3 \%$. The half-lives of acrinathrin and metaflumizone residues respectively were 3.8 and 5.9 days in field 1 and 9.2 and 4.5 days in field 2. The PHRLs 10 days before harvesting A. scaber were $0.610 \mathrm{mg} / \mathrm{kg}$ (field 1), $0.946 \mathrm{mg} / \mathrm{kg}$ (field 2) for acrinathrin, and $5.930 \mathrm{mg} / \mathrm{kg}$ (field 1), $5.147 \mathrm{mg} / \mathrm{kg}$ (field 2) for metaflumizone. This results can be used as basic data for the establishment of PHRL in A. scaber.
\end{abstract}

Keywords: Aster scaber, Dissipation pattern, Pesticide, Maximum residue limit (MRL), Pre-harvest residue limit (PHRL)

\section{Introduction}

Pesticides are very important resources in modern agriculture as their utilization for effective control of agricultural pests and weeds results in the increased productivity of cultivated crops $[1,2]$. Because pesticides are toxic to the human body and environment, policies related to pesticide safety, such as standards for safe use of pesticides are being implemented nationally to minimize risks to consumers and environment while ensuring high productivity. Efforts to mitigate the distribution and consumption of agri-foods exceeding the maximum residue limits (MRLs) of pesticide are being undertaken in Korea and other countries via the monitoring of pesticide residues in agricultural products distributed and imported for domestic consumption. In addition, the Korea Food and Drug Administration has expanded and systemized the monitoring of pesticide residues prior to shipment by establishing and applying a preharvest

\footnotetext{
*Correspondence: micai@kcl.re.kr

${ }^{1}$ Bio Division, Korea Conformity Laboratories, 8, Gaetbeol-ro 156 Beon-gil,

Yeonsu-gu, Incheon 21999, Korea

Full list of author information is available at the end of the article
}

residue limit (PHRL) to minimize damage to producers and consumers caused by the distribution of agricultural products which pesticide residue exceeds MRLs. The PHRL is calculated and established using the dissipation kinetics of pesticide residues per day [3].

This study aimed to obtain fundamental data for the establishment of PHRL through the calculation of pesticide residue dissipation patterns by determining residues each days, after spraying $A$. scaber with acrinathrin and metaflumizone, which are insecticides used for eliminating the kanzawa spider mite and tobacco cutworm, respectively, during cultivation.

\section{Methods \\ Chemicals and reagents}

Acrinathrin and methaflumizone, the insecticides used in this study, were used after dilution in $1,000 \mathrm{mg} / \mathrm{L}$ of acetonitrile solution purchased from Kemidas (Republic of Korea). Commercially purchased acrinathrin suspension concentrate (SC) $5.7 \%$ and metaflumizone SC $20 \%$ were used for field trials. The chemical structures and physichochemical properties of both pesticides are as shown 
Table 1 Chemical properties of acrinathrin and metaflumizone [4]

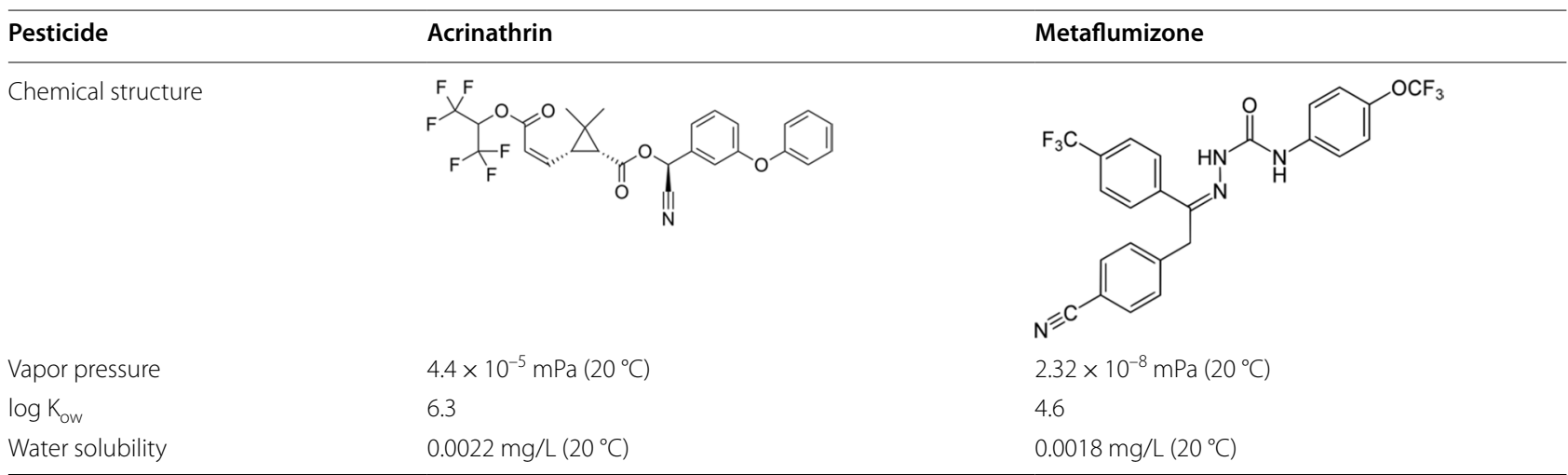

in Table 1. High-performance liquid chromatography (HPLC)-grade acetonitrile, methanol, and dichloromethane were purchased from J.T. Bake (USA). Solid reagents sodium sulfate and sodium chloride were purchased from Junsei chemical (Japan), and formic acid was purchased from Sigma Aldrich (USA). QuEChERS extraction kit $\left(\mathrm{MgSO}_{4} 4 \mathrm{~g}, \mathrm{NaCl} 1 \mathrm{~g}\right)$ was purchased from CTK (Korea). SPE Florisil cartridge $(500 \mathrm{mg}, 6 \mathrm{~mL}$ ) was purchased from Phenomenex (USA).

\section{Field trials}

Greenhouses distanced $20 \mathrm{~km}$ apart (latitude-wise) were selected for the field trials in locations Chungcheongnam-do Taean (Field 1) and Jeollanam-do Gwangyang (Field 2). The field trials were conducted from April to June and used the same variety of $A$. scaber purchased from Asia SEED Co., LTD. (Korea). Fields 1 and 2 were sowed on June 20 and April 28, respectively. The experimental fields were divided into replicates of $10-\mathrm{m}^{2}$ plots, each consisting of three replicates and a control plot. Pesticides were diluted and prepared according to the guidelines for the safe use of pesticides and were sprayed in different plots using a small engine-dispensing sprayer (MSB1015Li, MARUYAMA, Tokyo, Japan) (Table 2). Samples weighing $1 \mathrm{~kg}$ were collected $0,1,2,3,5,7$, and 10 days after insecticides spraying.
Collected samples were stored in polyethylene bags, kept in an ice box, and transported to the laboratory within $24 \mathrm{~h}$.

\section{Sample preparation}

Each sample transported to the laboratory was individually weighed and finely cut for sample preparation. Finely cut samples were stored in a refrigerator (below $-20^{\circ} \mathrm{C}$ ) for $>48 \mathrm{~h}$ and subsequently homogenized using dry ice and a homogenizer. Homogenized samples were divided into samples for analysis and storage and subsequently kept frozen (below $-20^{\circ} \mathrm{C}$ ) until residue analysis.

\section{Method establishment}

The method limit of quantification (MLOQ) was set the minimum concentration from the signal-to-noise ratio $(\mathrm{S} / \mathrm{N})$ of $>10$. Liquid chromatography with tandem mass spectrometry (LC-MS/MS) and HPLC conditions for the quantitative analysis of acrinathrin and metaflumizone are presented in Table 3. Individual $100 \mathrm{mg} / \mathrm{L}$ stock solutions of acrinathrin and metaflumizone were prepared by diluting $0.5 \mathrm{~mL}$ of $1000 \mathrm{mg} / \mathrm{L}$ standard solution of each pesticide with $4.5 \mathrm{~mL}$ of acetonitrile. Acrinathrin was diluted with acetonitrile, and the stock solution was matrix-matched at a ratio of 1:1 to prepare working

Table 2 Agricultural practice of acrinathrin and metaflumizone in Aster scaber

\begin{tabular}{|c|c|c|c|c|c|c|c|c|}
\hline \multirow[t]{2}{*}{ Pesticide } & \multicolumn{2}{|c|}{ Formulation } & \multicolumn{4}{|l|}{ Application } & \multirow[t]{2}{*}{$\mathrm{PHI}^{\mathbf{b}}$ (days) } & \multirow[t]{2}{*}{$M \operatorname{ML}^{\mathrm{c}}(\mathrm{mg} / \mathrm{kg})$} \\
\hline & Type & $A l^{a}$ & Dilution rate & $\begin{array}{l}\text { Spray amount } \\
\left(\mathrm{L} / \mathrm{m}^{2}\right)\end{array}$ & Spray No & $\begin{array}{l}\text { Interval } \\
\text { (days) }\end{array}$ & & \\
\hline Acrinathrin & $S C^{d}$ & 5.7 & 3000 & 0.05 & 2 & 7 & 7 & 3.0 \\
\hline Metaflumizone & SC & 20 & 2000 & 0.06 & 2 & 7 & 7 & 10.0 \\
\hline
\end{tabular}

\footnotetext{
a Active ingredient \%

b Pre-harvest interval

c Maximum residue limit

d Suspension concentrate
} 
Table 3 Analytical condition of acrinathrin and metaflumizone in Aster scaber

\begin{tabular}{|c|c|c|c|c|c|c|}
\hline Pesticides & \multicolumn{3}{|l|}{ Acrinathrin } & \multicolumn{3}{|c|}{ Metaflumizone } \\
\hline Instrument & \multicolumn{3}{|l|}{ Shimadzu LCMS 8045} & \multicolumn{3}{|c|}{ Agilent 1260 series HPLC } \\
\hline Column & \multicolumn{3}{|c|}{ Kinetex C18 (100 × 2.1 mm, 2.6 m, Phenomenex) } & \multicolumn{3}{|c|}{ 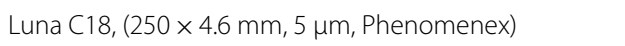 } \\
\hline \multirow[t]{8}{*}{ Mobile phase } & \multicolumn{6}{|c|}{$\begin{array}{l}\text { A: } 0.1 \% \text { formic acid in distilled water } \\
\text { B: } 0.1 \% \text { formic acid in acetonitrile }\end{array}$} \\
\hline & Time (min) & $A(\%)$ & $B(\%)$ & Time (min) & $A(\%)$ & $B(\%)$ \\
\hline & 0.1 & 45 & 55 & 0.5 & 80 & 20 \\
\hline & 15.0 & 15 & 85 & 3.0 & 5 & 95 \\
\hline & 16.0 & 10 & 90 & 5.0 & 5 & 95 \\
\hline & 23.0 & 10 & 90 & 6.0 & 80 & 20 \\
\hline & 24.0 & 45 & 55 & 7.0 & 80 & 20 \\
\hline & 30.0 & 45 & 55 & & & \\
\hline Flow rate & \multicolumn{3}{|l|}{$0.2 \mathrm{~mL} / \mathrm{min}$} & \multicolumn{3}{|l|}{$1.0 \mathrm{~mL} / \mathrm{min}$} \\
\hline Injection volume & \multicolumn{3}{|l|}{$2 \mu \mathrm{L}$} & \multicolumn{3}{|l|}{$20 \mu \mathrm{L}$} \\
\hline Detector & \multicolumn{3}{|l|}{ Triple-quadrupole } & \multicolumn{3}{|c|}{ Diode-array Detector (DAD) } \\
\hline Wavelength & \multicolumn{3}{|c|}{-} & \multicolumn{3}{|l|}{$285 \mathrm{~nm}$} \\
\hline \multirow{3}{*}{$\begin{array}{l}\text { Multiple reaction monitoring } \\
\text { (MRM) parameters }\end{array}$} & \multicolumn{3}{|c|}{ Precursor ion > Product ion (collision energy voltage) } & \multicolumn{3}{|l|}{-} \\
\hline & \multicolumn{6}{|c|}{$540.10>372.10(10.0)$} \\
\hline & \multicolumn{3}{|l|}{$540.10>285.25(36.0)$} & & & \\
\hline
\end{tabular}

solutions with concentrations of $0.025,0.05,0.1,0.5,1$, and $5.0 \mathrm{mg} / \mathrm{L}$. Metaflumizone was also diluted with acetonitrile to prepare working solutions with concentrations of $0.05,0.1,0.5,2.0$, and $5.0 \mathrm{mg} / \mathrm{L}$. The calibration curve was drawn according to the peak area versus the concentration of standard solutions, and linearity within the range of the calibration curve was obtained using the coefficient of determination $\left(\mathrm{r}^{2}\right)$.

\section{Recovery tests}

Recovery tests were performed at two concentrations with three replicates. The concentrations were $0.01 \mathrm{mg} /$ $\mathrm{kg}$ and $0.1 \mathrm{mg} / \mathrm{kg}$ for acrinathrin, and $0.5 \mathrm{mg} / \mathrm{kg}$ and $2.5 \mathrm{mg} / \mathrm{kg}$ for metaflumizone.

For acrinathrin, $10 \mathrm{~g}$ of the sample was treated with the standard solution to reach a concentration of $0.1 \mathrm{mg} / \mathrm{kg}$ and $1.0 \mathrm{mg} / \mathrm{kg}$, then $10 \mathrm{~mL}$ of acetonitrile was added, followed by vigorous shaking for $30 \mathrm{~min}$. The extract was added to a QuEChERS extract kit $\left(\mathrm{MgSO}_{4} 4 \mathrm{~g}, \mathrm{NaCl} 1 \mathrm{~g}\right)$, vigorously shaken, and then centrifuged at $4000 \mathrm{rpm}$ for $5 \mathrm{~min}$. Subsequently, $1 \mathrm{~mL}$ of supernatant was mixed with $1 \mathrm{~mL}$ of acetonitrile, followed by injection into the LC-MS/MS system for quantitative analysis.

For metaflumizone, $20 \mathrm{~g}$ of the sample was treated with the standard solution to reach concentrations of $0.5 \mathrm{mg} / \mathrm{kg}$ and $2.5 \mathrm{mg} / \mathrm{kg}$. To this, $100 \mathrm{~mL}$ of methanol was added, followed by homogenization for $5 \mathrm{~min}$ and then vacuum filtration. The extract was transferred to a $1,000-\mathrm{mL}$ separatory funnel, diluted with $400-\mathrm{mL}$ distilled water and 50-mL saturated saline, and then divided into $50-\mathrm{mL}$ fractions. Finally, the organic solvent layer was filtered with sodium sulfate to remove traces of water and vacuum evaporated at $40{ }^{\circ} \mathrm{C}$. An SPEFL $(1.0 \mathrm{~g}, 6 \mathrm{cc})$ cartridge was placed on the solid phase extraction device and prewashed with $5 \mathrm{~mL}$ of dichloromethane. The obtained eluate was dissolved with $5 \mathrm{~mL}$ of dichloromethane, loaded, and then eluted. The eluate was washed again with $5 \mathrm{~mL}$ of mixed solvent (dichloromethane: acetonitrile: $n$-hexane $=50: 1.5: 48.5$, $\mathrm{v} / \mathrm{v} / \mathrm{v}$ ), eluted with $5 \mathrm{~mL}$ of mixed solvent (dichlorometha ne:acetonitrile $=50: 50, \mathrm{v} / \mathrm{v}$ ), and then vacuum evaporated at $40{ }^{\circ} \mathrm{C}$. The final eluate was then redissolved in $4 \mathrm{~mL}$ of mixed solvent (acetonitrile:water $=50: 50, \mathrm{v} / \mathrm{v}$ ) and injected onto the high-performance liquid chromatography with diode-array detection (HPLC-DAD) system (Agilent 1100 Series, Agilent Technologies, Atlanta, GA, USA) for quantitative analysis (Table 3).

\section{Storage stability and residue levels by date}

To test storage stability, $10 \mathrm{~g}$ each of untreated samples was uniformly mixed into $0.1 \mathrm{mg} / \mathrm{kg}$ and $2.5 \mathrm{mg} / \mathrm{kg}$ of acrinathrin and metaflumizone standard solutions, respectively. Three replicates were maintained. The sample solutions were then kept in a freezer (below $-20{ }^{\circ} \mathrm{C}$ ) for 160 and 130 days, respectively, and subsequently tested following the same procedure used in the recovery tests. 


\section{Statistical analysis of half-life and PHRL}

Regression analysis of acrinathrin and metaflumizone residues per day on $A$. scaber was used to calculate the half-life and dissipation kinetics. F-test and t-test were performed to confirm the significance of the regression equation and dissipation kinetics with 95\% confidence levels. PHRL was estimated using the dissipation kinetics of two insecticides in A. scaber for 10 days.

\section{Results and discussion}

Temperature, humidity, and growth conditions for A. scaber cultivation

The average temperatures of Fields 1 and 2 throughout the duration of the field experiments were
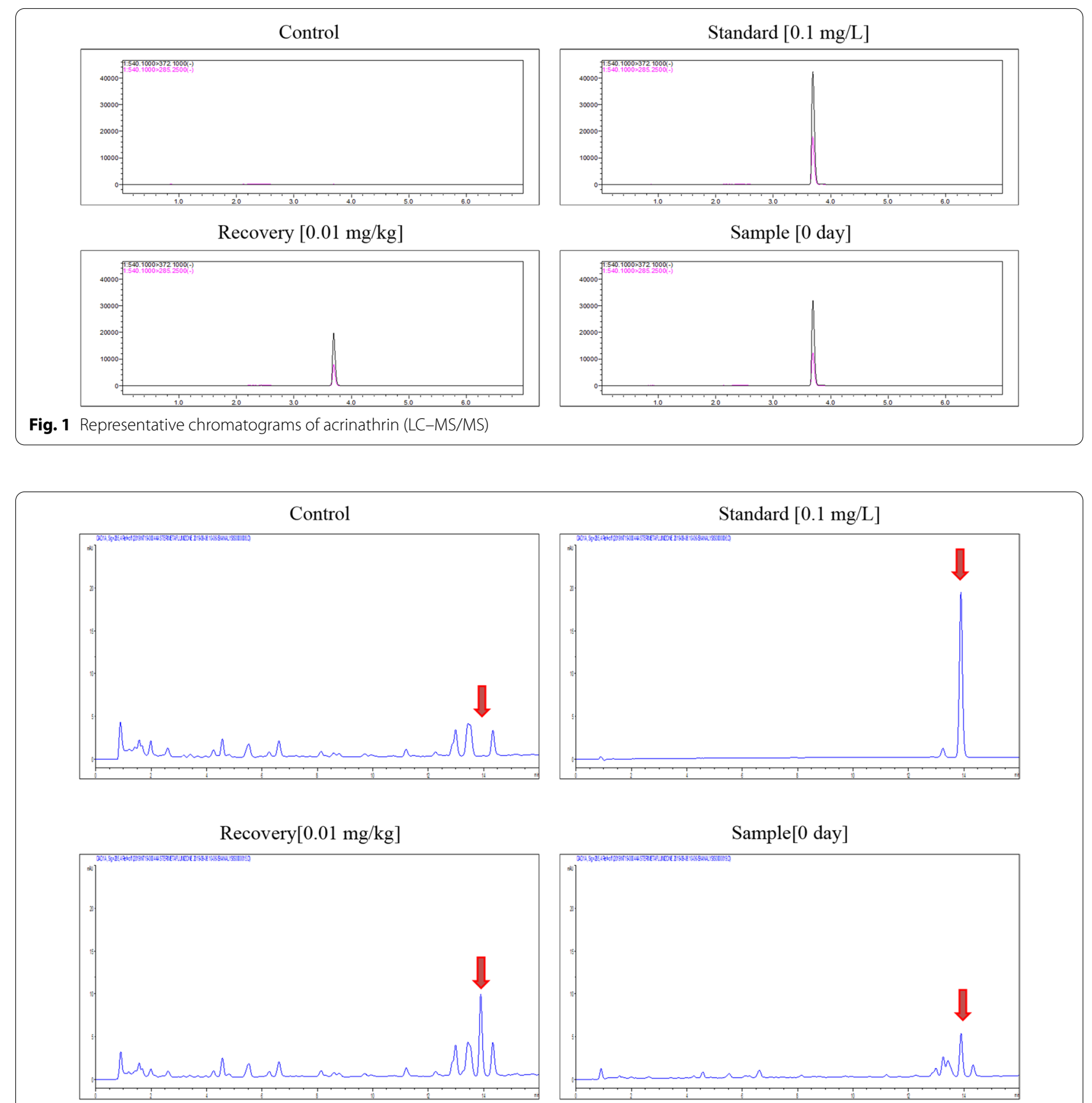

Fig. 2 Representative chromatograms of metaflumizone (HPLC-DAD)

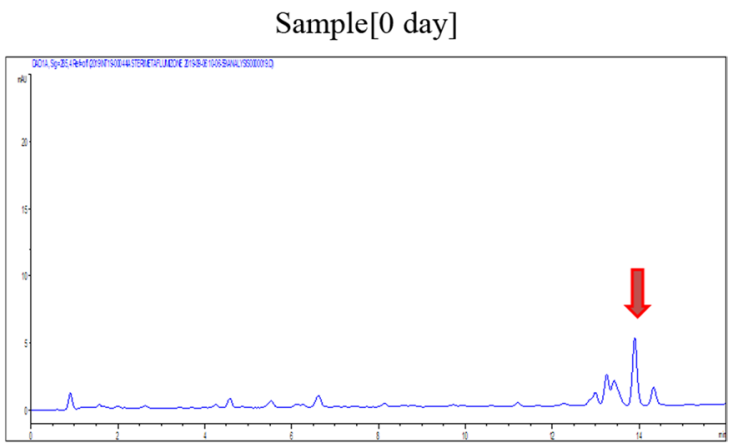


$16.9{ }^{\circ} \mathrm{C} \pm 2.6{ }^{\circ} \mathrm{C}$ and $17.1{ }^{\circ} \mathrm{C} \pm 1.8{ }^{\circ} \mathrm{C}$, and the average humidity was $76.4 \% \pm 4.7 \%$ and $77.4 \% \pm 14.1 \%$, respectively. The average weight per 20 bushels of $A$. scaber for $0-10$ days after pesticide spraying was $140.3 \pm 2.1 \mathrm{~g}$ on day 0 and $141.7 \pm 2.5 \mathrm{~g}$ on day 10 for Field 1 , and $134.0 \pm 10.1 \mathrm{~g}$ on day 0 and $141.7 \pm 10.6 \mathrm{~g}$ on day 10 for Field 2, both showing minor change during the duration of the field experiments.

\section{Method validation}

The method limits of quantitation (MLOQ) for acrinathrin and metaflumizone in $A$. scaber were 0.025 and $0.05 \mathrm{mg} / \mathrm{kg}$, respectively (Figs. 1, 2). The calibration curve for the standard solutions was obtained using peak area regression within the concentration range, and linearity was obtained using the coefficient of determination $\left(r^{2}\right)$. The equations calculated through regression analysis were as follows: $y=43,749.9 x+2,118.1$ (Field 1) and $y=42,257.6 x+1,602.8$ (Field 2) for acrinathrin, and $\mathrm{y}=1.518 \mathrm{x}-0.674$ (Field 1) and $\mathrm{y}=1.473 \mathrm{x}+0.004$ (Field 2) for metaflumizone. The coefficient of determination values for acrinathrin and metaflumizone were both $>0.999$, demonstrating high linearity. Recovery test results showed that the average recovery rates per concentration were $81.0 \%(0.1 \mathrm{mg} / \mathrm{kg})$ and $108.6 \%(1.0 \mathrm{mg} /$ $\mathrm{kg}$ ) for acrinathrin, and $109.2 \%(0.5 \mathrm{mg} / \mathrm{kg})$ and $95.8 \%$ $(2.5 \mathrm{mg} / \mathrm{kg})$ for metaflumizone. The coefficients of variation were all $<10 \%$, meeting the residue level analysis criteria of recovery rate of $70 \%-110 \%$ and coefficient of variation of $20 \%$, which are needed to establish PHRL (Table 4). During the quantitative analysis of acrinathrin using LC-MS/MS and metaflumizone using HPLC-DAD, we confirmed that the interference peaks had no influence on both the untreated and recovery samples. In storage stability tests, acrinathrin showed $89.4 \% \pm 4.5 \%$ recovery rate after storage for 160 days and metaflumizone showed $93.9 \% \pm 0.8 \%$ recovery rate after storage for 130 days, confirming that both resulted in neither decomposition nor loss during the sample storage period.

\section{Changes in residue levels during $A$. scaber cultivation period}

After acrinathrin and metaflumizone treatments, changes in their residue levels were observed over time during the cultivation period of $A$. scaber. Initial residue levels after acrinathrin spraying were $0.61 \mathrm{mg} / \mathrm{kg}$ and $0.95 \mathrm{mg} /$ $\mathrm{kg}$ for Fields 1 and 2, respectively. Similarly, initial residue levels after metaflumizone spraying were $5.93 \mathrm{mg} / \mathrm{kg}$ and $5.15 \mathrm{mg} / \mathrm{kg}$ for Fields 1 and 2, respectively. A comparison of the initial residue levels of acrinathrin and metaflumizone showed that metaflumizone levels were 9.7 times higher (Field 1) and 5.42 times higher (Field 2) than acrinathrin levels. Guidelines for the safe use of the insecticides acrinathrin and metaflumizone specify that both can be sprayed up to two times 7 days before harvest. Acrinathrin SC (5.7\% contained) was diluted 3,000 fold, whereas metaflumizone SC (20\% contained) was diluted 2000 fold. Thus, the amount of sprayed metaflumizone active ingredient was confirmed to be 5.3 times higher than that of acrinathrin (Table 2). Therefore, the difference between the initial residue levels of acrinathrin and metaflumizone found on $A$. scaber was determined to be caused by the difference between the amounts of the sprayed active ingredient.

Dissipation patterns and dissipation kinetics were calculated through regression analysis based on the pesticide residue levels of $A$. scaber according to the harvest date. Acrinathrin and metaflumizone residue levels decreased exponentially during the cultivation period of A. scaber. On the 10th day, the last day of collection, acrinathrin residue levels for Fields 1 and 2 were $0.27 \mathrm{mg} / \mathrm{kg}$

Table 4 Recovery (RCV) and storage (STR) test for acrinathrin and metaflumizone in Aster scaber

\begin{tabular}{|c|c|c|c|c|c|c|c|c|}
\hline \multirow[t]{3}{*}{ Pesticide } & \multicolumn{2}{|c|}{ Spiking level (mg/kg) } & \multirow{2}{*}{\multicolumn{3}{|c|}{$\frac{\text { Recovery (\%) }}{\text { Replicate }}$}} & \multirow{3}{*}{$\begin{array}{l}\mathrm{CV}^{\mathrm{b}} \\
\text { Mean } \pm \mathrm{SD}^{\mathrm{a}}\end{array}$} & \multicolumn{2}{|c|}{$\mathrm{MLOQ}^{c}(\mathrm{mg} / \mathrm{kg})$} \\
\hline & & & & & & & & \\
\hline & & & 1 & 2 & 3 & & & \\
\hline \multirow[t]{3}{*}{ Acrinathrin } & $\mathrm{RCV}$ & 0.1 & 83.3 & 82.7 & 77.1 & $81.0 \pm 3.4$ & 4.2 & 0.05 \\
\hline & & 1.0 & 105.6 & 111.3 & 108.8 & $108.6 \pm 2.9$ & 2.6 & \\
\hline & STR & 1.0 & 84.9 & 93.8 & 89.6 & $89.4 \pm 4.5$ & 5.0 & \\
\hline \multirow[t]{3}{*}{ Metaflumizone } & RCV & 0.5 & 111.2 & 107.9 & 108.6 & $109.2 \pm 1.7$ & 1.6 & 0.01 \\
\hline & & 2.5 & 96.6 & 95.9 & 94.9 & $95.8 \pm 0.9$ & 0.9 & \\
\hline & STR & 1.0 & 93.5 & 94.9 & 93.4 & $93.9 \pm 0.8$ & 0.9 & \\
\hline
\end{tabular}

\footnotetext{
a Standard deviation

${ }^{b}$ Coefficient of variation

${ }^{c}$ Method limit of quantification
} 

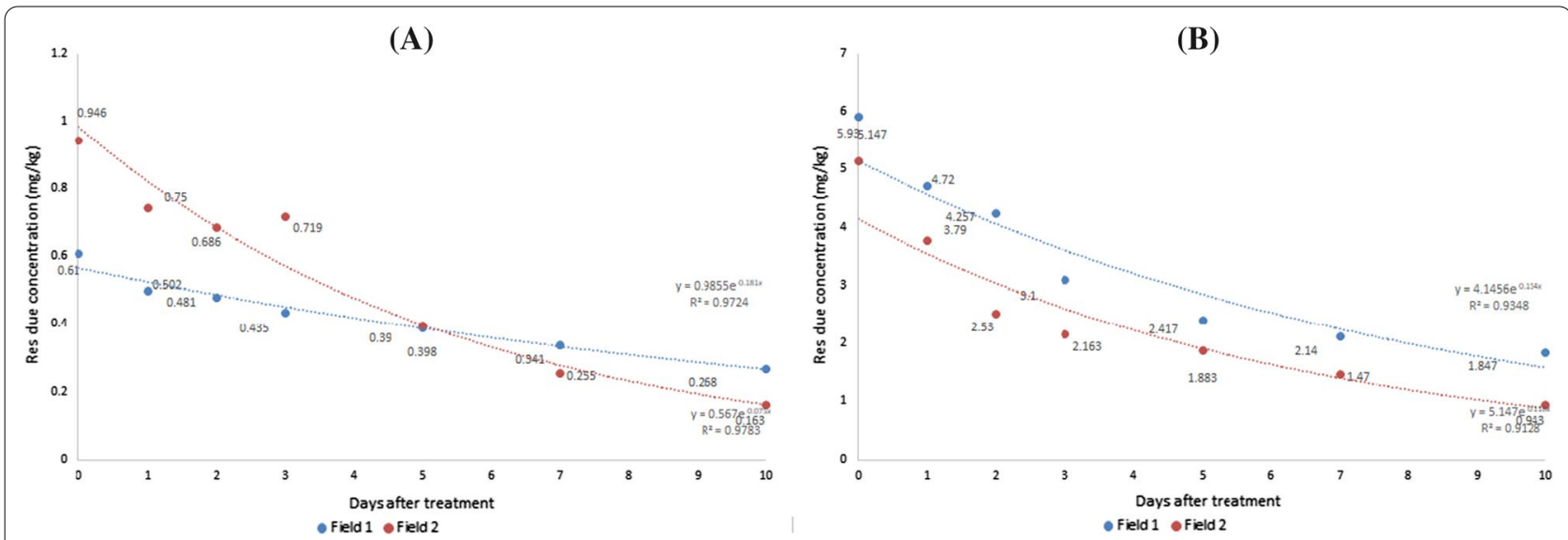

Fig. 3 Dissipation patterns of acrinathrin (A) and metaflumizone (B) in Aster scaber

and $0.16 \mathrm{mg} / \mathrm{kg}$, which were $44.3 \%$ and $16.8 \%$ of the initial residue levels, respectively; similarly, metaflumizone residue levels for Fields 1 and 2 were $1.85 \mathrm{mg} / \mathrm{kg}$ and $0.94 \mathrm{mg} / \mathrm{kg}$ corresponding to $31.1 \%$ and $18.3 \%$ of the initial residue levels, respectively. The preharvest intervals of acrinathrin and metaflumizone for $A$. scaber were both 7 days; acrinathrin residue levels for the corresponding date were $0.34 \mathrm{mg} / \mathrm{kg}$ and $0.26 \mathrm{mg} / \mathrm{kg}$ for Fields 1 and 2, and metaflumizone residue levels were $2.14 \mathrm{mg} / \mathrm{kg}$ and $1.47 \mathrm{mg} / \mathrm{kg}$ for Fields 1 and 2, which were below the pesticide MRLs of $3.0 \mathrm{mg} / \mathrm{kg}$ and $10.0 \mathrm{mg} / \mathrm{kg}$.

A regression equation for chemical residues per day for A. scaber was calculated through simple regression analysis, and the coefficient of determination values $\left(\mathrm{r}^{2}\right)$ were all $>0.9$, showing high correlation and determination (Fig. 3). The half-life of acrinathrin in A. scaber was 9.2 days (Field 1 ) and 3.8 days (Field 2), and that for metaflumizone was 5.9 days (Field 1 ) and 4.5 days (Field 2). Acrinathrin showed different chemical dissipation pattern and half-life compared with metaflumizone. This result indicates that the relatively low concentration of residue resulted in the difference between the field experiments. The lower $95 \%$ confidence interval of the dissipation kinetics was 0.0626 (Field 1) and 0.1509 (Field 2) for acrinathrin, and 0.0760 (Field 1) and 0.1076 (Field 2) for metaflumizone.

\section{Pesticide residue characteristics in $A$. scaber}

Factors that influence pesticide residue in agricultural crops include the pesticide's mechanism of action, formulation, and spraying method; the crop's cultivation method, shape, and growth rate; the weather conditions in the cultivation area; the shape and amount of the crop's villi; the surface area-to-weight ratio; the surface curvature; and the composition of the surface wax layer [5-9]. Unlike crops that show rapid growth, such as cucumber and broccoli, $A$. scaber did not show significant weight change throughout the experimental period of this study, and thus the dilution effect due to weight gain did not have a significant influence on the residue levels.

A. scaber showed little to no growth in the course of this experiment, rendering the dilution effect due to growth insignificant, and thus other factors, such as temperature, microorganisms, light, and the pesticide dilution factor, are deemed to have a greater influence on the pesticide residue levels during the cultivation period. A comparison of the half-life of acrinathrin between Field 1 and Field 2 revealed that Field 1 had a relatively longer half-life, which is believed to be influenced by low concentration variation and environmental factors. The halflives of methyoxyfenozide and novaluron on A. scaber have been reported to be 3.99 and 3.16 days for standard dose, and 5.98 and 5.53 days for double dose, respectively [10]. These were similar to the half-life of acrinathrin in this study. Further, the half-life of methaflumizone, which requires spraying relatively larger amounts of pesticide, in this study was similar to the double-dose half-lives reported previously.

Table 5 Recommended PHRLs of acrinathrin and metaflumizone in Aster scaber

\begin{tabular}{|c|c|c|c|c|}
\hline \multirow[t]{2}{*}{ Pesticide } & & \multicolumn{2}{|c|}{$\begin{array}{l}\text { Recommended PHRLs }{ }^{\mathrm{a}} \text { (mg/ } \\
\mathrm{kg} \text { ) }\end{array}$} & \multirow[t]{2}{*}{ MRLs (mg/kg) } \\
\hline & & $\begin{array}{l}10 \text { days } \\
\text { before }\end{array}$ & 5 days before & \\
\hline \multirow[t]{2}{*}{ Acrinathrin } & Field 1 & 0.610 & 0.268 & 3.0 \\
\hline & Field 2 & 0.946 & 0.255 & \\
\hline \multirow{2}{*}{$\begin{array}{l}\text { Metaflumi- } \\
\text { zone }\end{array}$} & Field 1 & 5.930 & 2.417 & 10.0 \\
\hline & Field 2 & 5.147 & 2.163 & \\
\hline
\end{tabular}

a Preharvest residue limits 
Accordingly, the half-lives of residual acrinathrin and metaflumizone vary depending on the amount of the pesticide sprayed and the dilution factor, with environmental factors also having a significant influence.

\section{Calculating PHRL of $A$. scaber}

The PHRL at the time of harvest is the residue at an established point in time prior to cultivation used to ensure that the pesticide residue does not exceed the residue limit. It is calculated by applying the lower $95 \%$ confidence interval of the residue's dissipation kinetics per day. The lower $95 \%$ confidence intervals of the dissipation kinetics for acrinathrin were 0.0626 (Field 1) and 0.1509 (Field 2), and those for metaflumizone were 0.0760 (Field 1) and 0.1076 (Field 2). The calculated PHRLs based on these values are shown in Table 5. PHRLs for A. scaber 10 days prior to harvest were $0.610 \mathrm{mg} / \mathrm{kg}$ (Field 1) and $0.946 \mathrm{mg} / \mathrm{kg}$ (Field 2) for acrinathrin, and $5.930 \mathrm{mg} / \mathrm{kg}$ (Field 1) and $5.147 \mathrm{mg} / \mathrm{kg}$ (Field 2) for metaflumizone.

\section{Conclusions}

This study established an analysis method for determining PHRL of acrinathrin and metaflumizone in A. scaber and used it for residue analysis per day during the cultivation period of in A. Scaber. Based on this, the half-lives and dissipation tendencies of pesticides were identified. Our research provides fundamental data that can be set up the PHRLs. This research will protect farmers and consumers from agriculture products in which pesticide exceeds MRLs.

\section{Abbreviations}

CV: Coefficients of variation; HPLC: High-performance liquid chromatography; LC-MS/MS: Liquid chromatography with tandem mass spectrometry; LOQ: Limits of quantitation; MLOQ: Method limit of quantification; MRL: Maximum residue limit; PHRL: Pre-harvest residue limit.

\section{Acknowledgements}

The authors would like to thank Enago (www.enago.co.kr) for the English language review.

\section{Authors' contributions}

$J K, K L, S K$, and JL performed the field experiment, sample preparation. JK, JL, and RK conducted sample analysis. JL and SL wrote the manuscript. JL revised the final manuscript. JL supervised the project and revised the final manuscript. All authors read and approved the final manuscript.

\section{Funding}

This research was supported by the Ministry of Food and Drug Safety, Republic of Korea (Grant Number: 17162MFDS010).

\section{Availability of data and materials}

Not applicable.

\section{Declarations}

\section{Competing interests}

The authors declare that they have no competing interests.

\section{Author details}

${ }^{1}$ Bio Division, Korea Conformity Laboratories, 8, Gaetbeol-ro 156 Beon-gil, Yeonsu-gu, Incheon 21999, Korea. ${ }^{2}$ Department of Veterinary Pathology, College of Veterinary Medicine, Seoul National University, 1 Gwanak-ro, Gwanak-gu, Seoul 08826, Republic of Korea.

Received: 19 October 2021 Accepted: 9 February 2022

Published online: 23 February 2022

References

1. Kim JE, Choi TH (1992) Behavior of synthetic pyrethroid insecticide bifenthrin and cyhalothrin in soil environment. Korean J Environ Agric 11:116-124

2. Krol WJ, Arsenault TL, Pylypiw HM, Incorvia Mattina MJ (2000) Reduction of pesticide residues on produce by rinsing. J Agric Food Chem 48:4666-4670

3. Lee DY, Jo HJ, Jeong DK, Goo YM, Hwang MR, Kang NJ, Kang KY, Kim JH (2018) Residual characteristics of pesticides used for powdery mildew control on greenhouse strawberry. J Agric Life Sci 52:99-106

4. Korea Crop protection Association (2020) 2020 Crop Protection Guidelines.

5. Ghadiri H, Rose CW, Connell DW (1995) Degradation of organochlorine pesticides in soils under controlled environment and outdoor conditions. J Environ Manage 43:141-151

6. Kim JB, Son BH, Chun JC, Im GJ, Im YB (1997) Effect of sprayable formulations on pesticide adhesion and persistence in several crops. Korean J Pestic Sci 1:35-40

7. Lee HS, Park YW (2005) Antioxidant activity and antibacterial activities from different parts of broccoli extracts under high temperature. Korean Soc Food Sci Nutr 34:759-764

8. Poulsen ME, Wenneker M, Withagen J, Christensen HB (2012) Pesticide residues in individual versus composite samples of apples after fine or coarse spray quality application. Crop Protect 35:5-14

9. Lee EY, Choe WJ, Lee HJ, Shin YW, Do JA, Kim WS, Chol DM, Chae KR, Kang CS (2010) Research on pesticides residue in commercial agricultural products in 2009. J Food Hyg Saf 25:192-202

10. Hong JH, Lim JS, Lee CR, Han KT, Lee YR, Lee KS (2011) Study of pesticide residue allowed standard of methoxyfenozide and novaluron on Aster scaber during cultivation stage. Korean J Pestic Sci 15:8-1

\section{Publisher's Note}

Springer Nature remains neutral with regard to jurisdictional claims in published maps and institutional affiliations.

\section{Submit your manuscript to a SpringerOpen ${ }^{\odot}$ journal and benefit from:}

- Convenient online submission

- Rigorous peer review

- Open access: articles freely available online

- High visibility within the field

- Retaining the copyright to your article

Submit your next manuscript at springeropen.com 